\title{
SOSIALISASI ANTI HOAX, ANTI NARKOBA, SERTA PENGEMBANGAN UMKM DI DESA KUBU KABUPATEN KUBU RAYA
}

\author{
SOCIALIZATION OF ANTI HOAX, ANTI DRUGS, AND UMKM \\ DEVELOPMENT IN KUBU VILLAGE, KUBU RAYA REGENCY
}

\author{
${ }^{1)}$ Dedi Saputra, ${ }^{2)}$ Wanty Eka Jayanti, ${ }^{3)}$ Eva Meilinda, ${ }^{4}$ Sri Murni \\ Universitas Bina Sarana Informatika Kampus Pontianak \\ *Email: dedi.dst@bsi.ac.id
}

\begin{abstract}
ABSTRAK
Perkembangan dunia digital saat ini semakin tidak terbendung, dimana setiap masyarakat baik kota maupun desa wajib memiliki pengetahuan tentang literasi dunia digital, hal ini dilakukan agar kedepannya masyarakat dapat mampu mengikuti perkembangan zaman. Salah satu kelompok masyarakat yang wajib mempelajari tentang literasi digital adalah Warga Desa Kubu, Kecamatan Kubu, Kabupaten Kubu Raya. secara umum, yang dimaksud dengan literasi digital adalah kemampuan menggunakan teknologi informasi dan komunikasi (TIK) untuk menemukan, mengevaluasi, memanfaatkan, membuat, dan mengomunikasikan konten/informasi, dengan kecakapan kognitif maupun teknikal dalam menangkal HOAX, narkoba dan memanfaatkan digital untuk upaya pengembangan UMKM. Saat ini masyaraat Desa Kubu masih mengalami kendala terkait memahami pengetahuan tentang dunia digital, seperti masih banyaknya orang orang yang tidak paham menggunakan perangkat digital, masih sering terpapar hoax, dan masih banyaknya yang tidak mengetahui tentang etika-etika yang ada didunia digital, bentuk-bentuk memerangi narkoba, dan pemfaatan digital untuk UMKM. Oleh karena itu kami dari Universitas Bina Sarana Informatika mengadakan kegiatan pengabdian masyarakat untuk mengatasi permasalahan permasalahan tersebut.
\end{abstract}

Kata Kunci : sosialisasi, Hoax, Narkoba, UMKM

\begin{abstract}
The development of the digital world is currently increasingly unstoppable, where every community, both urban and rural, is required to have knowledge of digital world literacy, this is done so that in the future people can be able to keep up with the times. One of the community groups who are obliged to learn about digital literacy is the Kubu Village Resident, Kubu District, Kubu Raya Regency. In general, what is meant by digital literacy is the ability to use information and communication technology (ICT) to find, evaluate, utilize, create, and communicate content/information, with cognitive and technical skills in preventing HOAX, drugs and utilizing digital for UMKM development efforts. Currently, the Kubu Village community is still experiencing problems related to understanding knowledge about the digital world, such as there are still many people who do not understand using digital devices, are still often exposed to hoaxes, and there are still many who do not know about the ethics that exist in the digital world, forms of fighting drugs, and using digital for UMKM. Therefore, we from Bina Sarana Informatika University held community service activities to overcome these problems.
\end{abstract}

Keyword : socialization, Hoax, Drugs, UMKM 


\section{PENDAHULUAN}

Perkembangan dunia digital saat ini semakin tidak terbendung, dimana setiap masyarakat baik kota maupun desa wajib memiliki pengetahuan tentang literasi dunia digital, hal ini dilakukan agar kedepannya masyarakat dapat mampu mengikuti perkembangan zaman. secara umum, yang dimaksud dengan literasi digital adalah kemampuan menggunakan teknologi informasi dan komunikasi (TIK) untuk menemukan, mengevaluasi, memanfaatkan, membuat, dan mengkomunikasikan konten/informasi, dengan kecakapan kognitif maupun teknikal.

Mudahnya mendapatkan informasi dari berbagai sumber khususnya media sosial, masyarakat dengan mudah terpapar informasi yang menyesatkan. Informasi yang belum terkonfirmasi kebenarannya (hoax), intensitas berita yang tidak jelas dan minim verifikasi(Wijaya, 2021). Kegiatan pengabdian terdahulu tentang sosialisasi Hoax menyatakan "Hoax bertujuan membuat opini publik, menggiring opini publik, membentuk persepsi, juga untuk having fun yang menguji kecerdasan dan kecermatan pengguna internet dan media social" (Wahyuni et al., 2021). Kegiatan pengabdian lainnya juga menyatakan Informasi yang telah yang bersumber baik individu maupun ketika telah terkirim dan dibaca oleh publik akan memberikan pengaruh pada emosi, perasaan, pikiran bahkan tindakan seseorang atau kelompok (Alfi \& Halwati, 2021).

Berdasarkan data dari Badan Narkotika Nasional (BNN), penyalahgunaan narkoba di Indonesia mengalami peningkatan 0,03\% pada 2019 dibandingkan 2017. Dengan kata lain, pada 2019, tercatat ada 3,6 juta pengguna narkoba, 63\% di antaranya pengguna ganja. Dari angka 3,6 juta pengguna narkoba, mengungkapkan, 70\% di antaranya adalah masyarakat dalam usia produktif, yakni 16-65 tahun(Humas BNN, 2021). Yang lebih menyedihkan lagi, dari angka tersebut, sebanyak $27 \%$ pengguna narkoba dari kalangan pelajar dan mahasiswa(Lenny Tristia Tambun / BW, 2021) Dalam pemberian pemahaman tentang pencegahan Narkoba, pengabdian sebelumnya menyatakan "Program Diseminasi Informasi dilaksanakan dalam bentuk kerjasama bersama beberapa media massa untuk memberikan informasi kepada masyarakat mengenai bahaya narkoba dan himbauan agar dapat menjauhinya" (Fadhli \& Anisah, 2019). Kegiatan pengabdian masyarakat lainnya bertujuan untuk menambah wawasan masyarakat tentang jenis dan bahaya narkoba bagi kesehatan, dan memengaruhi 
masyarakat agar menghindari penyalahgunaan narkoba. (Pradana et al., 2019). Kegiatan Pengabdian Kepada Masyarakat terdahulu lainnya bertujuan untuk memberikan pengetahuan tentang informasi dan upaya pencegahan dan pemberantasan dan penyalahgunaan peredaran gelap narkotika dan obat-obatan terlarang. Melalui Pendidikan dan Pelatihan bagi relawan anti Narkoba, diharapkan memberikan kontribusi bagi masyarakat baik secara teoritis maupun praktis dalam pencegahan maraknya peredaran narkotika. Kegiatan pendidikan dan latihan ini diharapkan menjadi wadah bagi masyarakat yang berkeinginan menjadi relawan anti narkoba. Kegiatan yang diselenggarakan secara sistematis danterencana serta disampaikan oleh pemateri yang kompeten dibidangnya diharapkan mampu memberikan ilmu dan praktek terkait informasi peredaran narkoba, akibat penyalahgunaan narkoba, kerelawanan, dasar hukum terkait narkoba, rehabilitasi medis dan sosial serta sel-healing. Kegiatan diklat mampu membangun jaringan relawan anti narkoba(Kurniawan et al., 2020). Perlu diketahui, pencegahan, penanggulangan penyalahgunaan, dan peredaran gelap narkoba merupakan tanggung jawab bersama guna mewujudkan kamtibmas yang aman dan kondusif. Harapannya, dapat terwujud stabilitas pembangunan nasional, masyarakat adil, makmur, dan sejahtera. Terdapat beberapa langkah yang dapat diperbuat. Pertama, selalu waspada dengan perkembangan teknologi, canggihnya teknologi membuat para pengedar dapat dengan mudah melancarkan niatnya untuk mengedarkan obat terlarang tersebut. Kedua, tanamkan keteladanan agar dapat memberi bimbingan dan dorongan untuk berbuat lebih baik. Ketiga adalah peduli, sekaligus hal paling penting untuk mencegah dan memberantas penyalahgunaan narkoba. Terdapat beberapa langkah yang dapat diperbuat. Pertama, selalu waspada dengan perkembangan teknologi, canggihnya teknologi membuat para pengedar dapat dengan mudah melancarkan niatnya untuk mengedarkan obat terlarang tersebut. Kedua, tanamkan keteladanan agar dapat memberi bimbingan dan dorongan untuk berbuat lebih baik. Ketiga adalah peduli, sekaligus hal paling penting untuk mencegah dan memberantas penyalahgunaan narkoba. Untuk penanggulangan penyalahgunaan narkoba diperlukan upaya yang terpadu dan komprenhensif yang meliputi upaya preventif, represif, terapi dan rehabilitasi Penyebab terjadinya penyalahgunaan narkoba disebabkan oleh beberapa faktor yang saling mempengaruhi satu sama lain, yaitu: 1) Faktor letak geografi Indonesia; 2) Faktor 
ekonomi; 3) Faktor kemudahan memperoleh obat; 4) Faktor keluarga dan masyarakat; 5) Faktor kepribadian; 6) Faktor fisik dari individu yang menyalahgunakannya. Metode pencegahan dan pemberantasan penyalahgunaan narkoba yang paling efektif dan mendasar adalah metode promotif dan preventif. Upaya yang paling praktis dan nyata adalah represif dan upaya yang manusiawi adalah kuratif serta rehabilitative.

Kegiatan pencegahan narkoba mengenal tiga cara yakni promotif, preventif dan advokasi yang berbentuk komunikasi, informasi dan edukasi baik kepada pemuda yang tidak maupun yang sudah terjerumus dan peran organisasi masyarakat untuk melakukan penyuluhan, konsultasi, dan pengawasan perilaku dengan pendekatan keagamaan, hukum dan Kesehatan.(Bakker et al., 2020)(Saputra, 2014). Saat ini masyaraat Desa Kubu masih mengalami kendala terkait memahami pengetahuan tentang dunia digital, seperti masih banyaknya orang orang yang tidak paham menggunakan perangkat digital, masih sering terpapar hoax, dan masih banyaknya yang tidak mengetahui tentang etika etika yang ada didunia digital, untuk itu kami dari Universitas Bina Sarana Informatika mengadakan kegiatan pengabdian masyarakat untuk mengatasi permasalahan permasalahan tersebut.

Salah satu kelompok masyarakat yang wajib mempelajari tentang literasi digital adalah Warga Desa Kubu. Adapun kegiatan ini akan dilaksanakan rutin setiap minggu, minimal satu minggu sekali selama sebulan dengan sasaran peserta adalah masyarakat yang berada disekitar Kampung Digital, baik itu anak anak, orang tua, bahkan remaja. Adapun kegiatan direncanakan kurang lebih 2 hingga 3 jam disetiap pertemuannya. dan materi akan disesuaikan dengan kebutuhan dari masyarakat. Adapun materi yang dimaksud yaitu tentang penguatan literasi digital bagi remaja dan ibu ibu, bidang bersosial media, pengenalan dan pemahaman masyarakat tentang UU ITE, serta tips dan trik jualan online bagi remaja dan ibu ibu di Desa Kubu.

\section{METODE}

Metode yang dilakukan dalam kegiatan PKM ini adalah dengan memberikan pelatihan dan workshop kepada masyarakat, dimana pelatihan akan diberikan dua kali seminggu, yakni setiap hari sabtu / minggu agar tidak menganggu kegiatan masyarakat. 
Adapun metode pelaksanaan yang kami lakukan tergambar melalu diagram dibawah ini

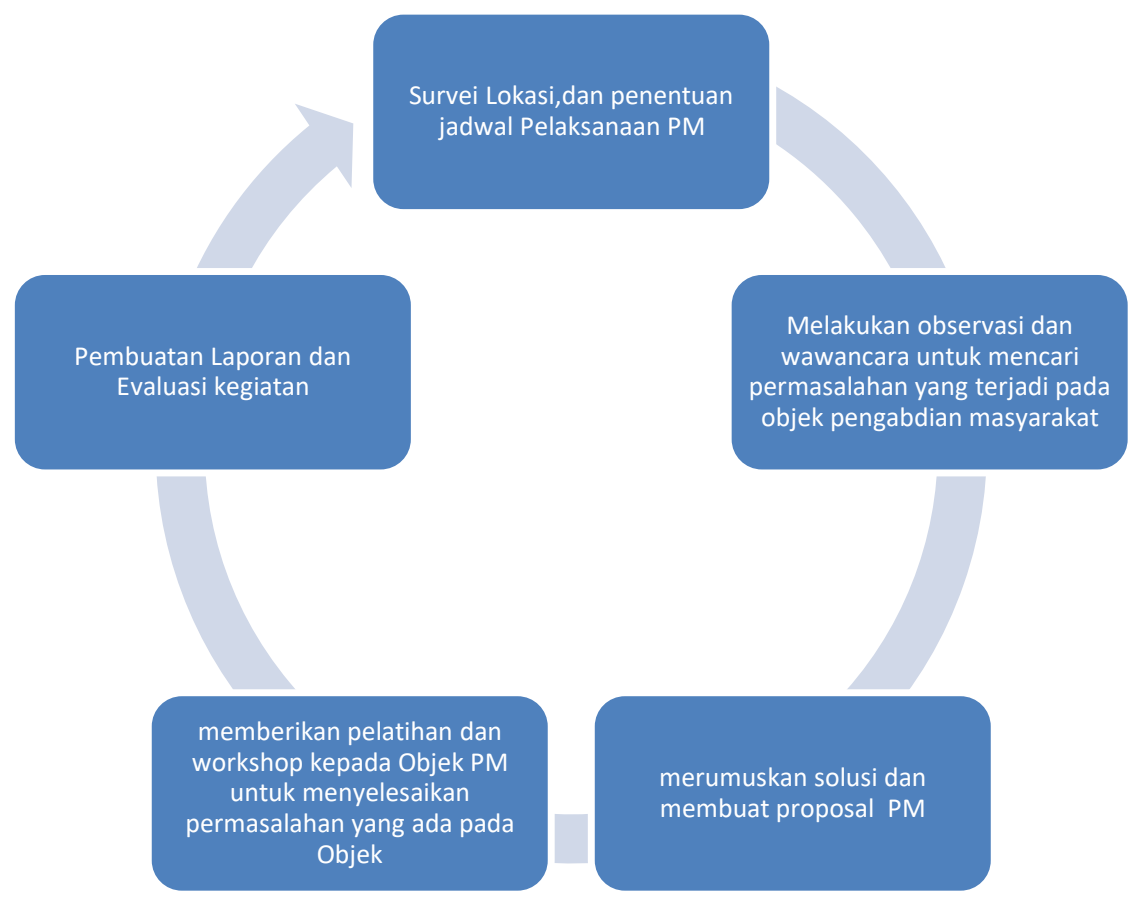

Gambar 1. Diagram Metode PKM

\section{HASIL DAN PEMBAHASAN}

\section{Analisis Situasi}

Masyarakat Desa Kubu merupakan kelompok masyarakat seperti biasa pada umumnya, yang rata rata terdiri dari bapak bapak, ibu ibu, remaja dan anak anak, namun uniknya di sini adalah masyarakat disini sangat aktif sekali dalam melakukan pertemuan, baik pertemuan kampung ataupun pertemuan arisan dan lain sebagainya.

Masyarakat disini terdiri dari berbagai macam mitra, ada mitra produktif yaitu mitra yang memiliki usaha namun masih dijalankan secara konvensional, ada pula mitra yang tidak produktif seperti ibu ibu rumah tangga, dan remaja remaja yang masih dalam umur Pendidikan, ada pula mitra yang mengarah ke ekonomi produktif, masyrakat sendiri sudah memiliki tempat yang representative untuk mengadakan pelatihan dan workshop untuk warga sekitar, Adapun gambaran dari mitra dijelaskan melalui beberapa foto dibawah ini Melihat potensi masyarakat disini sangat disayangkan apabila tidak diberikan edukasi tentang literasi digital mengingat literasi digital sangat penting bagi 
masyarakatk khususnya di bidang wawasan. Berikut dokumentasi foto dari kegiatan PKM saat berlangsung.

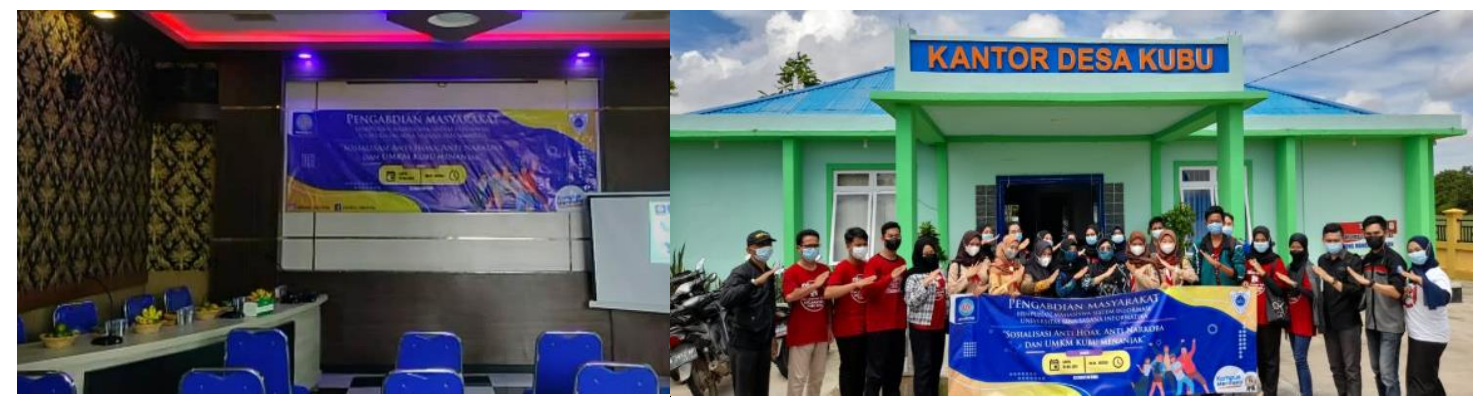

Gambar 2. Pelaksanaan PKM

\section{Peta Lokasi Mitra}

Lokasi Desa Kubu berada di Kecamatan Kubu. Akses menuju desa tersebut, melalui kecamatan Rasau jaya dengan menggunakan akses darat kurang lebih 1,5 jam dan 2 jam melalui transportasi air. Penduduk Desa tersebut merupakan suku melayu. Adapun jarak tempuh dari Universitasn Bina Sarana Informatika ke desa Kubu adalah -+ 44,7 km.

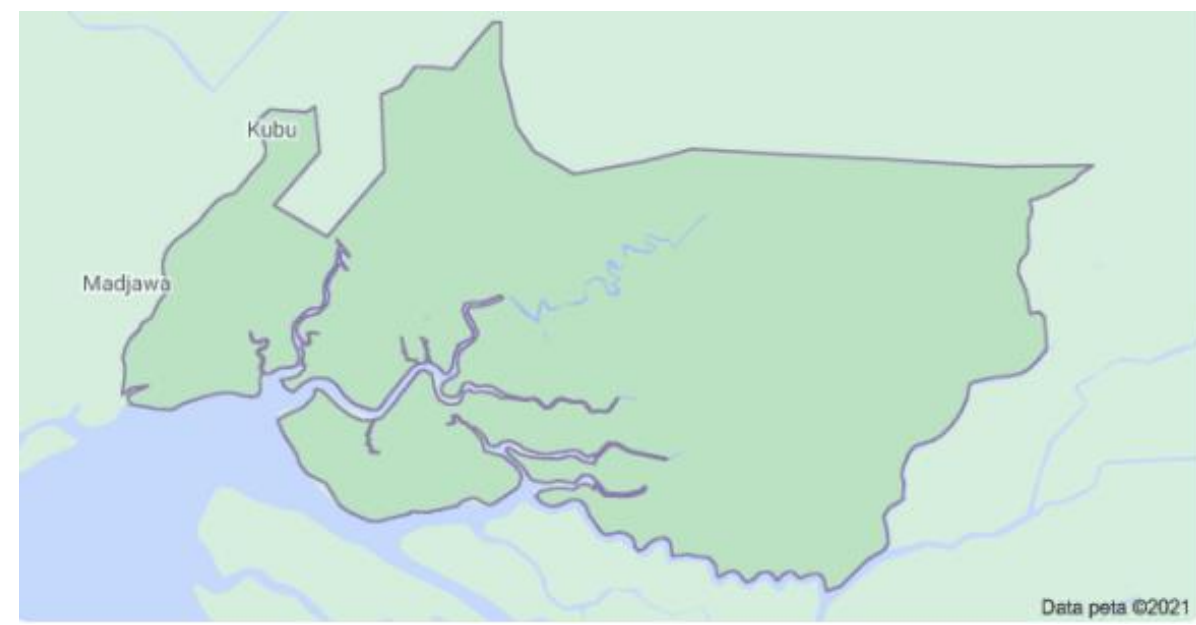

Gambar 2. Peta Lokasi Mitra PKM

\section{Permasalahan Mitra}

Berdasarkan pendahulan, dan Analisa kondisi masyarakat ditemukan beberapa permasalahan yang dihadapi oleh mitra kampung Digital Kapuas River yang merupakaan binaan dari GRADASI Kalimantan Barat diantaranya yaitu:

a. Masih banyak masyarakat yang menjadi sasaran penyebaran hoax karena minimnya pengetahuan tentang anti hoax 
b. Banyak sekali usia produktif yang berada di Desa tesebut, sehingga berpotensi menjadi salah satu target penyalah gunaan narkoba jika tidak memiliki pengetahuan memadai mengenai Narkoba

c. Adanya potensi wisata yang dimiliki desa kubu, sehingga perlu pemahaman dalam menghadapi era wisata.

d. Mayoritas Masyarakat Desa Kubu adalah nelayan dan petani. Hasil ikan dan tani tersebut tentu saja butuh pemahaman dalam mengelola dan memasarkannya. Hal ini bisa menjadi sumber potensi berkembangnya UMKM di desa tersebut.

\section{Manfaat Yang Diperoleh (Outcome)}

Sesuai dengan permasalahan yang sudah dijabarkan diatas, dalam kegeiaatan pengabdian masyarakat universitas bina sarana informatika dengan Sosialisasi Anti Hoax, Anti Narkoba, Serta Pengembangan Umkm Di Desa Kubu Kabupaten Kubu Raya memiliki beberapa manfaat dan outcame diantaranya yaitu:

a. Masarakat sekitar sangat berterima kasih kepada tim dari universitas bina sarana informatika karna dengan adanya kegiatan ini masyarakat mendapatkan program pembinaan dan pelatihan untuk meningkatkan skill masyarakat

b. Masyarakat Desa Kubu yang berusia produktif mendapatkan pemahaman tentang anti hoax, narkoba dan UMKM menanjak yang baik, dan sudah bisa membedakan mana informasi yang benar dan mana informasi yang tidak benar serta dapat kembali mengedukasi masyarakat yang lain

c. Masyarakat sekitar semakin berkembang potensinya karena meningkatnya pengetahuan masyarakat tentang penglolaan dan pengembangan potensi wilayah yang berkaitan dengan Digitalisasi

b. Masyarakat umur 40 keatas sudah memahami apa itu hoax, apa ciri ciri hoax, dan bagaimana cara mengatasinya sehingga bisa dan mampu menangkal hoax untuk dirinya sendiri

c. Masyarakat sekitar semakin mampu dan paham tenang Undang undang ITE dan bisa menghidari terjerat dari UU ITE

d. Masyarakat setempat memahami UU Narkotika dan mulai faham bagaimana memerangi narkoba. 
e. Masyarakat semakin mampu menggunakan sosial media dengan baik dan benar, tanpa terpapar berita hoax ataupun cara cara yang salah dalam menggunakan media sosial

f. Ibu ibu semakin paham dan mahir tentang pengetahuan terkait penjualan digital, dan dapat memasarkan produk peroduk mereka menggunakan media media digital

\section{SIMPULAN}

Kegiatan pengabdian masyarakat Universtias Bina Sarana Informatika dengan tema Penguatan Literasi Digital Bagi Warga warga Desa Kubu, Kabupaten Kubu Raya dapat disimpulkan kegiatan seperti ini sangat bermanfaat sekali bagi masyarakat dikarenakan masih banyak sekali masyarakat yang tidak memahami cara memerangi Hoax, narkoba, dan meningkatkan UMKM dengan baik, sehingga banyak yang menjadi korban ataupun pelaku kejahatan didunia maya tanpa mereka menyadarinya. Masyarakat Desa Kubu sangat berterima kasih kepada Universitas Bina Sarana Informatika karna dengan adanya kegiatan seperti ini mereka masih bisa belajar tentang ilmu ilmu baru terutama dengan literasi digital, hoax dan digital marketing Masyarakat Desa Kubu berharap kegiatan ini tidak hanya dilaksanakan sekali saja melainkan dilakukan secara rutin di kegiatan kegiatan yang lain, misal ketika pengajian, atau ketika ada rapat RT. Masyarakat memahami betul pentingnya memahami literasi digital dan mulai terbuka wawasannya dan semakin berhati hati dalam menggunakan sosial media dan mengenali ciri-ciri penyalahgunaan narkotika.

\section{DAFTAR PUSTAKA}

Alfi, I., \& Halwati, U. (2021). PENCEGAHAN PERILAKU UJARAN KEBENCIAN (HOAX) DI MASYARAKAT (Studi Kasus di Desa Cinangsi Kecamatan Gandrungmagu Kabupaten Cilacap Jawa Tengah). Al-Idaroh: Media Pemikiran Manajemen Dakwah, 1(2), 24-35.

Bakker, F. F., Putra, A. P., \& Putri, R. T. (2020). The Role of ASEAN in Tackling the Main Issues of Transnational Crime in the Southeast Asia Region. Journal of Law and Border Protection, 2(1), 47-58.

Fadhli, T. A., \& Anisah, N. (2019). Strategi Komunikasi Seksi Pencegahan Badan Narkotika Nasional Provinsi (BNNP) Aceh dalam Menyosialisasikan Anti Narkoba Melalui Media Massa di Kota Banda Aceh. Jurnal Ilmiah Mahasiswa Fakultas Ilmu Sosial \& Ilmu Politik, 4(1). 
Humas BNN. (2021). Menanggulangi Narkoba Di Era Pandemi Covid-19 Menuju Indonesia Bersinar. https://bnn.go.id/kepala-bnn-ri-mengajak-universitasgunadarma-dalam-menanggulangi/

Kurniawan, I., Mulyanto, R., \& Marwiyah, M. (2020). Diklat Relawan Anti Narkoba sebagai Partisipasi dalam Pemberantasan Penyalahgunaan Narkoba. Abdi: Jurnal Pengabdian Dan Pemberdayaan Masyarakat, 2(1), 11-17.

Lenny Tristia Tambun / BW. (2021). 27\% Pengguna Narkoba dari Kalangan Pelajar dan Mahasiswa. https://www.beritasatu.com/nasional/792291/27-penggunanarkoba-dari-kalangan-pelajar-dan-mahasiswa

Pradana, D. A., Amelia, D., Shavera, F., \& Purnamasari, O. (2019). SOSIALISASI JENIS DAN BAHAYA NARKOBA BAGI KESEHATAN PADA IKATAN PEMUDA WARU RW 05 PAMULANG BARAT, TANGERANG SELATAN. Prosiding Seminar Nasional Pengabdian Masyarakat LPPM UMJ.

Saputra, D. (2014). Pengembangan Strategi Belajar dan Pembelajaran Menggunakan Model Multimedia Interaktif (sebuah Tinjauan). Jurnal Khatulistiwa Informatika, 2(1).

Wahyuni, W. S., Fithri, B. S., Harahap, D. A., \& Kartika, A. (2021). Sosialisasi Sanksi Penyebaran Berita Bohong (Hoax) berdasarkan Undang-undang Informasi dan Transaksi Elektronik. Jurnal ABDIMAS Budi Darma, 2(1), 42-45.

Wijaya, S. H. B. (2021). PENYULUHAN LITERASI MEDIA TENTANG HOAX DI KALANGAN GENERASI MUDA DESA JUWOK. Dedikasi: Jurnal Pengabdian Kepada Masyarakat, 1(1), 1-10. 